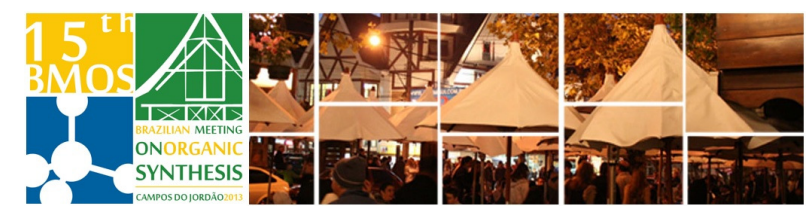

\title{
Benzo[b]thiophene dimerization: A promising experimental finding directed to the C-3 functionalization with aryl alcohols.
}

\author{
Javier Romero-Parra, ${ }^{*}$ Hernán Pessoa-Mahana and C. David Pessoa-Mahana. \\ Departamento de Farmacia, Facultad de Química, Pontificia Universidad Católica de Chile, Avenida Vicuña \\ Mackenna 486, Casilla 306, Santiago 22, Chile.
}

*jhromero@uc.cl

Keywords:Benzo[b]thiophene, heterocycle, alcohols.

\section{INTRODUCTION}

The benzo[b]thiophene functionalization with benzyl groups at $\mathbf{C}-\mathbf{3}$ has been a synthetic challenge. Indeed, up to the date, few efforts have been successful in the achievement of this goal, and all of them involving drastic experimental conditions ${ }^{1,2}$. In this opportunity, trying to synthesize new benzo[b]thiophene frameworks, we inform the nonexpectable obtaining of benzo[b]thiophene dimers linked by a C-3 bond. In this sense, we think that this interesting experimental finding could lead to develop a new method to synthesize 3- substituid benzo[b]thiophene with different kinds of benzyl alcohols.

\section{RESULTS AND DISCUSSION}

As a part of our efforts directed to the obtaining of new series with affinity by human endocannabinoid receptor $\mathrm{CB} 1$, we designed a synthetic strategy resumed on scheme 1 . Unexpectedly, during the alcohol reduction (step d) along with the alkyl derivatives ( $V$ for example) we obtained benzo $[b]$ thiophenes dimers linked between the $\mathbf{C - 3}$ of the heterocycle and the carbon of the alcohols in the aliphatic chain (figure 2).

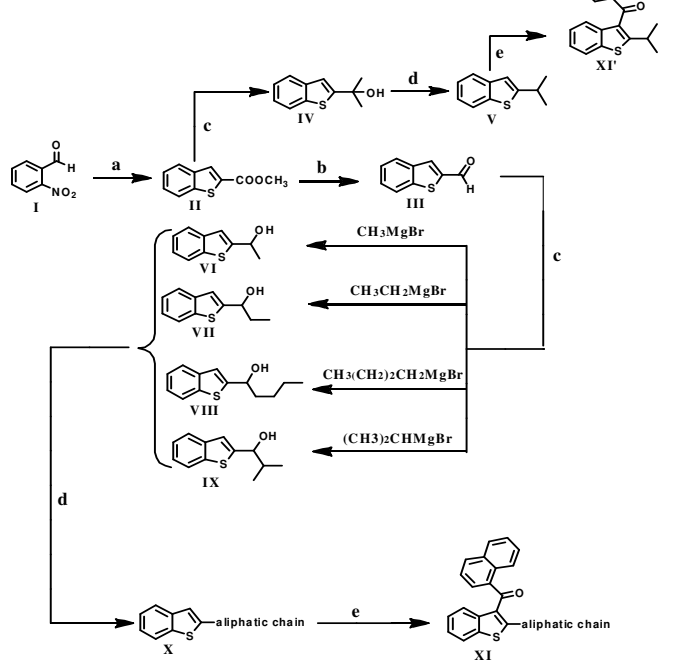

Scheme 1: $\mathrm{SHCH}_{2} \mathrm{COOCH}_{3}, \mathrm{~K}_{2} \mathrm{CO}_{3}$, DMF. b) DIBAH, $\mathrm{N}_{2}$, THF, $-78^{\circ} \mathrm{C}$. c) Corresponding Grignards, THF, $\mathrm{N}_{2}$ d) $\mathrm{NaBH}_{4}, \mathrm{TFA}$, $\mathrm{CH}_{2} \mathrm{Cl}_{2}$. e) 1-Naphthoyl chloride, $\mathrm{AlCl}_{3}, \mathrm{ClCH}_{2} \mathrm{CH}_{2} \mathrm{Cl}$.

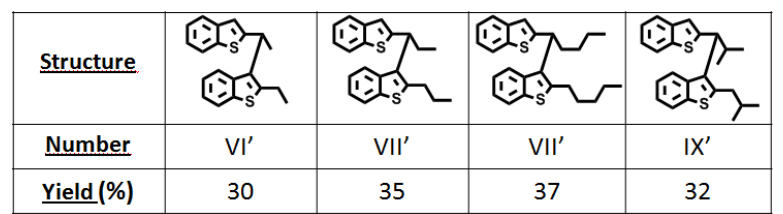

Figure 2: Dimers of benzo[b]thiophenes formed on the alcohol reduction (step d) and their respective yields.

The dimerization mechanism probably involves the carbocation intermediate which is produced during the alcohol reduction. Subsequently this carbocation is attacked by the C-3 atom of another benzo[b]thiophene molecule (scheme 2a).

This result could give an interesting light in the search of an efficient strategy directed to get C-3 substituted benzo[b]thiophene. An example with benzyl alcohol is shown on scheme $2 b$.

a)

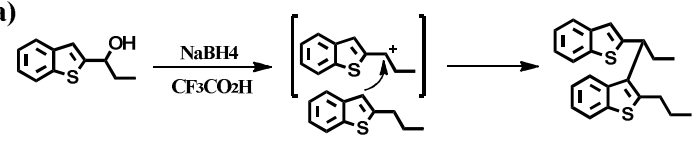

b)

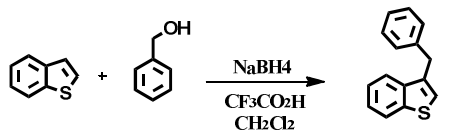

Scheme 2: a) Mechanism of carbocation production and subsequently nucleophilic attack of 3-C benzo[b]thiophene.

b) Example of a useful reaction among the heterocycle and vinyl alcohols.

\section{CONCLUSION}

We report a novel class of benzo[b]thiophene dimers formed through the generation of a carbocation intermediate and the $\mathrm{C}-3$ benzo[b]thiophene. This result represents a probable new strategy directed to the obtaining of 3 - substituted benzo[b]thiophene. New experimental examples of this reaction are currently ongoing in order to define the scope of this strategy.

\section{ACKNOWLEDGEMENTS}

The authors are grateful to FONDECYT (grant no. 1100493) and CONICYT for doctoral support.

\section{REFERENCES}

${ }^{1}$ Peter, D.C.; Andrew, K.;Shaun, T.M.;James, G.K.Y. Alkylation of Thiophenes and Preparation on Benzothiophenes Using Modified Montmorillonite Clay Catalyst. Phosphorus, Sulfur, Silicon Rel. Elem. 1994, 95,441-443.

${ }^{2}$ Peter, D.C.;Shaun, T.M. Benzylation of Benzo[b]thiophene using $\mathrm{ZnCl}_{2}$ - Modified Montmorillonite Clay. Phosphorus, Sulfur, Silicon Relat. Elem. 1995, 105, 157-62. 